
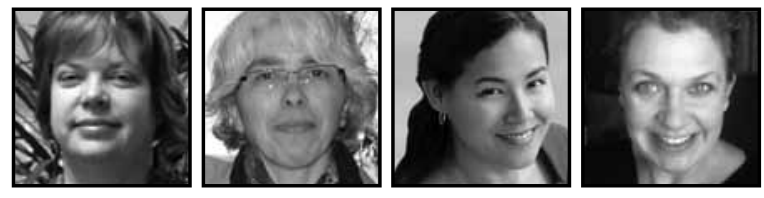

\title{
Graduate Research Writing: A Pedagogy of Possibility
}

Cecile Badenhorst, Cecilia Moloney, Janna Rosales, and Jennifer Dyer, Memorial University

\section{ABSTRACT}

Graduates often find conceptualizing and writing long research projects an arduous alienating process. This paper ${ }^{1}$ describes a research writing intervention conducted at Memorial University in Newfoundland with two groups of graduate students (Engineering and Arts). One small part of the workshop was devoted to creative "sentence activities." Our argument is that these creative activities contributed to re-connecting students to themselves as researchers/writers and to others in the group. The activities engaged students in language literally, metaphorically, and performatively.

\section{Introduction and Context}

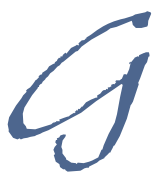

raduate students rarely express their experience of writing research dissertations in enthusiastic terms. For the most part, they convey their experience in terms of anxiety, distress, suffering, agony, and even torture. The plethora of advice books on how to complete a Master's or PhD thesis that have saturated the market are testament to the desperation among many students to find some compass, some north star, to latch on to and guide them through this journey (Kamler \& Thomson, 2008). Once finally at road's end, many students express a loss of confidence after completing their Master's or PhD dissertation when intuitively one would expect the opposite. After many years of focussing on a research topic and hour upon hour devoted to writing, one would expect students' self-assurance 
to grow with their increasing content knowledge and expertise. Why is the research dissertation process defined by struggle? Does it necessarily have to be? What can be done to change this? At Memorial University, a group of faculty from different disciplines (Education, Engineering and Applied Science, Arts) were drawn together by these questions. We wanted to explore the possibility of introducing graduate students to new ways of thinking about their research.

\section{Why Is Graduate Research Writing Defined by Struggle?}

One key reason why students find writing difficult is because, as Bartholomae (1985) wrote of undergraduate student writing: "Every time a student sits down to write for us, he[/she] has to invent the university for the occasion" (p. 4). What Bartholomae suggests is that students write within a context that is fluid, evolving, and constantly changing. Negotiating fluctuating writing discourses is difficult for students, mostly because the requirements are hidden. To be successful, a student needs to understand the institutional and disciplinary values and expectations. Learning the secret life of research and research writing happens at a largely tacit level. Language conventions, required genres, and even thinking styles are often governed by disciplinary norms. Many of these conventions are subtle even to experienced scholars, yet students are expected to know them without explicit instruction (Parry, 1998). Universities consist of discourse communities that have ways of structuring writing (genres), ways of doing research, ways of asking questions, and ways of using language (Cain \& Pople, 2011). To participate in a discourse community and to be taken seriously one must be able read, speak, and write the discourse (Northedge, 2003; Wrigglesworth \& McKeever, 2010). Far from being explicit or even stable, these hidden requirements must seem like "a set of secret handshakes and esoteric codes" (Sommers, 2008, p. 153), particularly to newcomers. By the time a student reaches the graduate level, he/she will have divined the writing requirements for an undergraduate degree in some way. When they begin their graduate program, they soon realize that the rules have changed yet again.

A second reason why graduate writing is defined by struggle is that few programs offer institutionalized graduate research writing courses. Graduate research is cognitively complex: students are required to undertake research, embark on large projects, develop conceptual frameworks and, especially for PhDs, contribute to the knowledge of a discipline or field. Writing in academia, requires not only subjectmatter knowledge or knowledge of genres, but also how to write "convincingly to expert readers" in the field (Tardy, 2005, p. 325). Students will often receive training in content areas, and research methodology through prescribed courses. They may get 
mentoring through supervision in operationalizing their research and collecting data. But rarely do they get training on how to pull these disparate areas together. Added to this, the nature of research itself is chaotic, messy, and multi-faceted. Students are required to draw threads from the chaos and translate these into a coherent linear written text without much formal guidance beyond supervision. For this reason, there are increasing calls in the literature for systematic graduate research training in a variety of forms (Aitchison, 2009; Clughen \& Hardy, 2011; Ens, Boyd, Matczuk, \& Nickerson, 2011; Ferguson, 2009; Haas, 2011; Maher et al., 2008).

Third, a common assumption is that writing is a transparent activity (Parker, 2002). One does research and then writes it up. An "academic literacies" perspective takes the approach that writing is complex and involves many embedded literacies that are situated in specific contexts (Lea \& Street, 2006). Consequently, writing a research thesis is not merely reporting on research but about making ontological and epistemological claims (Lillis \& Scott, 2007). We perform our academic identity through our research writing (Hyland, 2002). It is the way we participate in the discourse, how we are positioned by the discourse, and how we negotiate that positioning. Structures of argument, citation practices, and making evaluations on previous research have underlying epistemological roots (Parry, 1998). What forms of data are acceptable and how data is valued changes from discipline to discipline and sometimes within disciplines (Badenhorst, 2008). Disciplines and discourse communities are themselves fluid structures and are continually changing (Parker, 2002). While writing is about language and skill, it is, indeed, much more.

\section{The "Othering" of Graduate Students}

We argue that all of the above contributes to many graduate students experiencing a process of "Othering" when they engage in research writing. Krumer-Nevo and Sidi (2012) describe Othering as the way moral codes of inferiority and difference are subtly established over time. It is the "critical discursive tool of discrimination and exclusion against individuals" (p. 300). Otherness happens through rules of behaviour, conventions, and performance in a discourse. Often the process is seen as neutral and transparent, and becomes accepted as natural. In their study they found four mechanisms of Othering at work:

1) Objectification is subjugation of individual complexities by ignoring personal perspectives. The individual person is hidden behind the general features of the group or cohort.

2) Decontextualization is the detachment from an immediate context of place and 
time. Behaviours become generalized rather than specific responses to particular circumstances.

3) Dehistorization is the focus on the present. Divorced from personal individual histories, the present becomes distorted.

4) Deauthorization where texts created are supposedly autonomous, objective, and authorless. Writing is not an author's interpretation but the views of an omniscient narrator with an external reality.

These mechanisms of Otherness produce "alienation and social distance" (p. 300).

When writing in academic contexts, students are faced with these four mechanisms of Othering. Personal histories are often subjugated by prevailing discourses on academic writing that promote third-person, distant, passive, objective, and neutral positions. Conservative, rule-bound conventions characteristic of academic writing (Fulford, 2009; Northedge, 2003) often decontextualize and depersonalize content. Academic writing is often seen by students as impersonal and dry where they must separate their personalities from their research or writing. The self must be subordinate to the rigid conventions and authorial anonymity (Hyland, 2002). The process of researching and writing as strictly mediated by the discourse community is restrictive and "militates against creativity and individuality" (Cain \& Pople, 2011, p. 49).

Krumer-Nevo and Sidi (2012) further suggest that methods to write against Othering would include using 1) narratives to enable contextualization, historicization, and subjectivity; 2) dialogue which brings together the personal and subjective of the other, and acts against objectification and dehistoricization because the subject is present; and 3 ) reflexivity which acts against the (apparent) authoritative stance of the researcher. Critical reflexivity questions the stance of the researcher as an all-knowing claimer of truth. When the author demonstrates his/her processes of interpretation and conclusion-making, it emphasizes the text and writing as personal and partial. Reflexivity positions the researcher/writer in the text and reveals the researcher's "epistemological, ontological, methodological premises" (p. 305).

Krumer-Nevo and Sidi (2012) pose their argument in the context of researchers writing on and of their "subjects," but we found their work applicable on two levels. First, how students themselves are Othered through academic writing practices and, second, how students perpetuate that Othering when they write about their "subjects." 


\section{Introducing Creativity}

Our research team's collective history involved many hours of grappling with how to nurture graduate students as writers within disciplinary constraints and processes of Othering in contexts where graduate research training is seen as only necessary in the format of once-off, add-on workshops. How could we incorporate the complexity, the fluidity, the contradictions, the hidden rules of research writing as well as the explicit knowledge of genres, argument, research conceptualization and so many other crucial bits of information and process?

We drew on an existing workshop, which had successfully been applied in the South African context (Badenhorst, 2007), and adapted it to suit the disciplinary contexts at Memorial (Rosales, Moloney, Badenhorst, Dyer, \& Murray, 2012). We applied for and received funding to pilot the program. The result was an intensive, cocurricular, multi-day workshop. The pilot was conducted with a relatively small cohort of students from Memorial University's Graduate Program in Humanities and the Faculty of Arts (A\&H) in Fall 2011 (9 participants) and a second offering occurred in Winter 2012 with graduate students from the Faculty of Engineering and Applied Science (E) (13 participants). The 9 and 13 refer to the numbers of students who completed all components of the workshop. The total number of students attending was 17 in each offering, 34 in total. Many who attended were international students. Research areas varied considerably and included sports, poetry, the esoteric, music anthropology, and philosophy from the humanities group and electrical, computer, process, civil, ocean, and naval architecture, and mechanical in the engineering group. Each offering of the workshop involved seven mornings of class time, which lasted 3.5 hours each. The workshop was divided into two parts to simulate two stages of the writing process: composition (Part 1, four consecutive mornings) and revision (Part 2, three consecutive mornings). Daily homework was assigned to reinforce key learning points and for students to adapt learning to their own research contexts. Between the two Parts, participants had about a month to work on the first draft of their chosen research writing project.

Each of the seven workshop mornings was divided into three sections. In the first section, the homework from the day before was discussed in groups using specific feedback strategies. In the second section, activities and facilitated dialogue gave participants information and models on academic discourses relevant to graduate research (what counts as evidence in the discipline, how arguments work, research writing genres, etc.). They were also guided through theories of writing and creativity (process writing, what writing does, why writing is difficult, why creativity is important, identity and writing, how criticism affects writing self-efficacy, how academic 
writing is situated in a discourse of criticism, etc.). The last part of the morning was devoted to "play" activities intended to allow and encourage participants to move out of their usual ways of writing. Students were supplied with a copy of Badenhorst (2007) which contained materials, notes, and examples. They were also given additional references, and models of research and writing specific to their disciplines.

Creativity was a key theme throughout the workshop. Our purpose was to present writing and research genres, rules, and conventions but then to introduce the notions of possibility, choice, and the Self in writing and research. We sought to encourage flexible minds (Zerubavel, 1995) that would allow students to embrace the chaos of research rather than to only limit and control it. We carefully chose classroom settings that were as un-classroom-like as possible and conducive to creative thinking. Tables and chairs were arranged in groups to reflect a more "studio" style of learning. On each table we placed piles of blank coloured paper and a mug of coloured felt-tip markers. We removed all blue and black markers and asked students to write only on coloured paper with coloured markers, preferably their favourite colours. We also asked students to use their paper in "landscape" mode and not the regular "portrait" style. As we explained to participants, the purpose for using coloured paper and pens was to shift them out of habitual ways of doing things and to move them into changing their way of seeing their research. Throughout the workshop we asked students to sketch their research, to draw concept maps, to free write, to "play" with their research ideas.

We talked about Billy Collins' poem, Introduction to poetry, (http://www.loc. gov/poetry/180/001.html) where he says "I ask them to take a poem/and hold it up to the light/like a colour slide." He ends: "But all they want to do/ is tie a poem to a chair with a rope/ and torture a confession out it." We urged students to hold their research up to the light, turning it this way and that to see how the light shone through it, to drop a mouse in it and to see which way it crawled out and not torture a confession out of it. We asked them to write/draw using activities that were metaphorical and often illogical. Again the purpose was to allow students to "see" their research with new eyes, to unpack hidden assumptions, and to work through inconsistencies and contradictions.

Initially some students were sceptical of the activities but over the duration of the workshop they increasingly found value in them. By the end, they happily engaged in a range of creative activities. In part, the success of this component of the workshop was due to a set of activities, "the sentence activities," conducted in the last hour of each day in the first week. It is these activities that we would like to 
explain and highlight in this paper. The sentence activities were just one set of activities among many others but they played a crucial role in the workshop.

\section{The Sentence Activities}

For the last hour of each of the four days in Part 1 of the workshop, we introduced students to four sentences: The statement, the question, the exclamation, and the command. The inspiration for these activities was taken from Paul Matthews, Sing me the creation (1994), a sourcebook for writing poetry. Matthews argued that all language circulates around and between these sentence structures. We used the sentences to focus students' attention literally on how to construct sentences and paragraphs, metaphorically on what using these sentences can mean, and also performatively (Austin, 1975) on what these sentences do. Participants were asked to do the activities quickly and not to think too much or to censor themselves. Specifically, we talked about self-criticism and how negative inner talk often serves as an editor in writing, correcting before we have even thought through what we want to say.

\section{The statement.}

We began with the statement as it is the sentence that students are generally most comfortable using. The statement is the comfort zone of academia because it states, it names, it describes, it defines, and it gives information. Academic writing is most often about naming and defining. The statement is the voice of reason where a writer views the world and comes to conclusions about it. Statements are powerful because it allows a writer to name differences and to state truths (this is a chair, that is not). The statement, Matthews (1994) argues, aims to be correct and wise: "Statement is the power that human beings have to name differences, to distinguish between I and you, dark and light, cat and cabbage" (p. 20).

After explaining the sentence, we asked students to do a number of activities. The activities were drawn from Matthews (1994) and Badenhorst (2007). Only a sample of activities are included here. We scaffolded the activities by moving from the concrete to the abstract. We used M.C. Escher's lithograph "Relativity" (http:// www.mcescher.com/) to frame to concrete activities. "Relativity" was selected because it was a combination of the rational/logical with the chaotic/illogical to help students relate to the chaotic yet rational research process. The activities moved from "Relativity" to the classroom, to more abstract issues, to their research, and finally to themselves. For example: 
- Write three statements about the Escher lithograph

- Write three wise statements and three unwise statements about "Relativity"

- Write three truthful statements and three untruthful statements about "Relativity"

- Look around the classroom and write a statement that only you can see

- Write a statement explaining how this room is different from other rooms

- Write a statement of certainty and one of uncertainty

- Write a statement on the "big picture" of your research

- Write three "I am..." statements.

Students were given between 10-20 of these activities, depending on the size of the group and how fast they worked through them. Participants were quite comfortable writing statements and this provided an easy way into these activities that would continue to push them out of their comfort zones as the days went on. Despite this, students sometimes found it difficult to do some of the activities. For example, in writing untruthful statements they would ask: "Am I supposed to do it like this? Is this right? How do I know?" We did not provide answers or guidance and reminded them that they were "play" activities and to "let go." Once the activities were finished, all groups around a table were asked to read their responses aloud to each other and to select responses to share with the larger group as a whole. We did not give criteria for the selection but left it open to the group. We did pose the possibility that they might want to share the funniest, the most innovative as opposed to the "best." We also suggested that if they wanted to share more than one response for each activity that was fine too. Initially there were many questions around what was "right," what they were supposed to do, and what everyone else was doing. By the end of the week, groups were quite happy to contribute in ways that suited them. After the group discussions, the groups then shared their chosen responses to the larger class. The facilitators used this to direct discussion around language, words, academic conventions, and possibilities. For example, what happens when you name something, when you claim a truth? How do you do this in research? In writing? What counts as truth in your discipline? For the final activity, each person read his or her response to the whole group. This served to acknowledge the personal in the researcher/writer and the groups bonded considerably over these activities.

\section{The question.}

The second sentence was the question. The question moves a writer into uncertainty (Matthews, 1994). The stability of the statement gives way to the ambiguity of the question. Questions cast doubt on truth and are about being receptive and opening up to a response. They are about possibilities, dialogue, receptivity as well as 
interrogation and cross-examination: "Question implies a quest - to find an answer, someone to answer us. Without a question we are forever shut out from the inner life of another" (Matthews, 1994, p. 66). The activities included:

- Write three questions about the Escher lithograph

- Write three profound questions and three silly questions about "Relativity"

- Write three unusual questions about "Relativity"

- Write an interrogative question about the room, write an uncertain question about the room

- Write a question that tests the truth of the room

- Write an answer on a sheet of paper, fold the paper to hide what you've written, pass it to a partner who writes a question without looking at the answer

- Write a question and answer about your research

- Since questions are about quests, what is your quest in life, research or otherwise. Do a free-write.

The first day's activities broke the ice and by the second day, students were much more comfortable doing these activities. We asked students to change tables and sit with people they did not know or had not worked with before. The atmosphere in the classroom was one of focused concentration interspersed with laughter, side-comments and joking. Students were asked to provide three sentences rather than just one because it allowed them to move beyond their initial surface thoughts. Often the first sentence response was similar in the groups but numbers 2 and 3 were different. This reinforced the unique nature of individuals, their particular writing style, and their distinctive voice. Many students were surprised at their responses, at the uniqueness of their answers, and of how appreciative their audience was of their writing. Reading the responses aloud was important in helping them hear their distinct voice even if their responses were similar to others'. The group work provided a writer/audience context where the students knew they would have an audience for their writing. The discussion revolved around uncertainty in research, about a dialogue between writers and readers, and about receptivity. The final activity focused on why participants were doing the research they had chosen, what motivated them, and what kept them going. This was a powerful and emotional activity but also affirming for individuals, the group, and facilitators.

\section{The exclamation.}

The third sentence was the exclamation, the most difficult sentence for graduate students since most had been schooled not to use exclamations. As Matthews suggested: "Exclamation is language as direct expression of the inner life - to 
clamour, to cry out - its ideal being to sound the heart's tone truly. So often the voice of our education insists that we withdraw from talk about our feelings" (Matthews, 1994, p. 94). The exclamation is the outcast sentence in academic contexts because it is spontaneous and excited. There is no time to think or to formulate correct sentences. It is a form of delight and surprise but also horror. There is no detached third person author with the exclamation. Exclamation activities included:

- Write three exclamations about the Escher lithograph

- Write three exclamations of excitement and three exclamations of horror about "Relativity"

- Write three unusual exclamations about "Relativity"

- Write a detached exclamation about the room

- Write a long exclamation and a short exclamation about the room

- Write a heartfelt apology for handing in work to your supervisor late

- Write a statement then change it into an exclamation

- Write about an "aha! moment" in your research

- Exclamations open the heart in wonder. Write about what opens your heart in wonder (research or otherwise).

Although this sentence was difficult for some students in the context of their research, most relished these activities and gave full reign to their exclamations. This sentence opened the discussion on passion in research and why it was important for writing. We talked about conventions and disciplinary requirements that prevented any exclaiming sentences in research writing but where one could subtly convey interest, fascination, and inspiration in writing. We discussed writing with active and passive verbs and how the passive carries connotations of truth and how active verbs humanize writing. The final activity, again, focused on the person and made the link between the individual and the research. Most students expressed a passion for their research and felt a release at being able to express this.

\section{The command.}

The final sentence, the command, is about power, control, and authority. One commands when one wants to compel, dominate, or to order. Sometimes we have the right to command. "Command is language as deed, where the sentence is dynamic, imposing will on the world - not what language says, but what it does," proposes Matthews (1994, p. 134). We suggested to students that in research contexts, command is the authority that comes as a result of naming, questioning, and exclaiming. That once we know a research area inside and out, you can claim authority in writing. To achieve that end, the students were asked to: 
- Write three commands about the Escher lithograph

- Make an ordinary command and an unusual one of the room

- Draw"command"

- Write a long command and then change it to a one-word command

- Write three male/masculine commands and female/feminine commands

- State what you can authoritatively say about your research

- Write a paragraph about your research and begin with a command

- Some people are naturally statement-makers, or questioners, or exclaimers or commanders. Which are you? Which sentence are you drawn to?

By this stage students were comfortable in completing these activities and were no longer surprised at what they were asked to do. They also stopped questioning themselves and would write freely. The discussion here revolved around authority in writing: who has it, how does one write authoritatively, can one give away authority in writing, and so on. At this point, we also introduced the idea of how we use our authority as researchers, how we "represent" subjects of research, and whose voices appear in the writing of research.

The final activity was a reflection on how individuals worked as researchers and writers. Many of them found this activity surprising and informative. For example, if students reflected that they were exclaimers, it added to their understanding of why academic writing was sometimes a struggle.

For each of the sentences, we began by asking all students to stand and walk around the classroom and say statements, questions, exclamations, and commands out loud. We wanted them to hear how these sentences sounded and how they changed depending on content, context, and audience. We also wanted to acknowledge the embodied nature of language and writing. The Arts and Humanities cohort embraced this activity but the Engineering students found this less enjoyable.

The sentence activities sought to make participants aware of sentences and words and how they are used in particular contexts (Escher lithograph, room, research, personally). We hoped they would transfer this awareness into their own research. We wanted them to "see" sentences with new eyes and not to take them for granted. We wanted them to see the possibilities and the choices in terms of language, conventions, and personal preferences. We also used the sentences to discuss issues like the holistic researcher/writer who was not compartmentalized into separate boxes of "home" and "university." Rather, we wanted them to see how they were influenced by the type of research they did and their writing processes. The activity, 
"write a statement on something only you can see," allowed many students to realize that they did have a unique perspective on the world and to develop the confidence to use this in their research. Finally, we used the sentences to talk about the process of doing research and structuring writing: naming, questioning, understanding with awe, and, ultimately, knowing.

\section{Student Comments}

Alongside the workshops, the team conducted research. The key purpose of the accompanying research was to study the overall workshop pedagogy for its effectiveness in transforming student perspectives of research and writing. The data collected included observations during the workshops, workshop data collection (samples of student work, reflections on activities), pre- and post-surveys, and program evaluations. We are also in the process of collecting longitudinal interview data to explore the long-term effects of the workshop intervention over time. We deliberately did not collect samples from the "sentence activities." These activities played a crucial role in building trust, developing group dynamics, and nurturing individuals. We were cognizant of the damage any form of surveillance could do. Since we were committed to freeing students to write in an uncensored manner, collecting and scrutinizing their work seemed counter-productive. We did, however, ask students to reflect on the sentence activities and on the element of "play" in general.

Some students commented on the element of fun and how different this was from usual emotions they felt when it came to writing:

It [was] enjoyable. There [was] no constraint on my mind. Very relaxed. (Engineering [E])

I think it was a fantastic opportunity to feel free to write whatever I wanted. (Arts \& Humanities $(\mathrm{A} \& \mathrm{H})$

I think the sentence activity was very good. I enjoyed it very much. Although it was ... kind of fun but it [was about] different ways of thinking different things. (E)

...the humdrum of daily life and leading the life of a grad student with work, studies, and social life had taken something out of me completely and this is writing just for the fun and joy of writing. $(\mathrm{A} \& \mathrm{H})$

Others commented on the activities in relation to collegiality and the broader group: 
It was a fun activity ... it made everything light and bright. You got to know people, and how they think. I liked it. (E)

I found that people think differently when they look at the same picture. Some people think and write about drawing details while others may think about the whole concept and background idea. It was very interesting that I found it hard to make simple statements... although the drawing was complicated. I did not expect to have difficulty. (E)

The comments below illustrate that participants recognized the multiple layers to the sentence activities:

Yesterday's activity was fun and strange! At first glance, it was easy but it was not because you have to look at things in a different way and also, I found it useful for my last night's writing. (E)

Research is serious, to me, but maybe it can also be fun, just like using coloured pens to write down whatever you want to write on the fancy papers. I am the one who has the choice/option and can make the decision. (E)

Yes, I am thinking differently. I find using coloured pens and paper useful [smiley face] at least it makes the hard problem seem friendly and lovely. Now I am confident to write something and think about something. (E)

Some of the play seems not closely related to writing at first glance, but after reflection on it. I find the questions asked quite relevant to writing. These questions make me think about my research and my writing from a different perspective. (E)

Some of the activities opened my eyes to the potential of creativity in writing that I had not thought possible... l loved the use of the Escher print "Relativity," really interesting trying to grapple with that one. So many different and interesting men and women in this workshop from so many different backgrounds as well as cultural backgrounds. (A\&H)

I liked [the sentence activities] because I discovered I'm an organic writer that has tried to be too logical and formal. (A\&H)

I enjoyed very much the creativity and the ... fun of the writing process. I found it simple, yet deep as concept and practice. $(\mathrm{A} \& \mathrm{H})$

...I feel encouraged to not be afraid to keep submitting creatively researched and creatively written assignments. $(\mathrm{A} \& \mathrm{H})$ 


\section{Discussion and Conclusion}

What we have argued here is that students experience a process of Othering that separates them from their personal histories, personal interests, and their role as author with voice in their writing. Students often learn "one way" to write in academic contexts and writing experiences are defined by few choices. In contexts where many of the rules are unwritten, obscure, and hidden, it is difficult to gauge right and wrong ways of writing except through a random process of hit and miss. Constantly being on guard and under the surveillance of assessment creates writers who are cautious, conventional, and seek conformity.

Graduate students have the added challenge of pulling together cognitively complex fields into coherent, linear, lucid research dissertations. Research methodology, content areas, and dissertation writing are rarely grouped together in graduate research training. We developed a workshop that drew together these threads. One small aspect of the workshop focused on creativity in writing and thinking about research. The "sentence activities" played a particular role in the workshop. KrumerNevo and Sidi (2012) suggest that methods for working against Othering include using 1) narratives, 2) dialogue, and 3) reflexivity. We argue that these sentence activities encompass these three methods.

Throughout the activities, and particularly the final activity of each day, was an opportunity for students to write their own stories, their own narratives, to contextualize their own experience, and to link their personal identities to their researcher identities. By reading their writing aloud, participants began to hear their own unique voice as opposed to a disembodied ventriloquized academic voice, which they had become accustomed to using in their writing. Working in groups gave these writers an immediate and supportive contextualized audience. Linking research to the personal, re-connected students to themselves as whole people with histories and a sense of self. These activities also connected individuals to others in the group.

The sentence activities, although in some senses literal in that students became aware of sentence structure and construction, were also metaphorical. They showed what the different sentence types can mean in academic contexts. The truthbearing nature of the statement, for example, was disrupted from its assumed natural and normal position of power. The dialogue that resulted from the engagement in what sentences mean in contexts and time and how they can change or be changed allowed students to see through the "natural" and "normal." We also opened the discussion on what the sentences do and how they perform academia. Exclamations, for 
example, convey passion and are most often exiled from academic writing. This ongoing dialogue is crucial for students themselves as researchers/writers but also for how they conduct research and how they "write" their subjects.

The sentence activities also encouraged reflexivity by questioning the authority of the researcher, how this comes to be written, what alternatives or choices there are and how one can write differently. Participants had often never thought through how they came to conclusions or whether their conclusions carried authority. This growing awareness allowed them to make choices on how to conduct themselves as researchers ethically and poetically. The sentence activities showed students that their unique perspectives were based on "epistemological, ontological, methodological premises" (Krumer-Nevo \& Sidi, 2012, p. 305). Awareness of these premises allowed writers/researchers to see themselves aside and in relation to others and not merely as an unvoiced monolithic group subject to the dictates of a discourse.

The key outcome of the sentence activities was to surface the self above rigid conventions and authorial anonymity, to connect that self to others who may be undergoing similar processes of alienation, to begin a dialogue that connected rather than Othered, and to encourage a reflexivity where students could recognize the purpose of the activities. While we cannot claim to have reversed the process of Othering through one short workshop, we feel we have begun a process that would be greatly enhanced by more systematic institutionalized graduate training programs along these lines.

\section{Note}

1. This research has been supported by an Instructional Development grant from Memorial University of Newfoundland in 2011-12. Ethical approval for this research was granted by the Interdisciplinary Committee on Ethics in Human Research at Memorial University of Newfoundland.

\section{References}

Aitchison, C. (2009). Writing groups for doctoral education. Studies in Higher Education, 34(8), 905-916.
Austin, J.L. (1975). How to do things with words. Oxford: Clarendon Press. 
Badenhorst, C. (2007). Research writing: breaking the barriers. Pretoria: Van Schaik.

Badenhorst, C. (2008). Dissertation writing: $A$ research journey. Pretoria: Van Schaik.

Bartholomae, D. (1985). Inventing the university. In M. Rose (Ed.). When a writer can't write: Studies in writer's block and other composing-process problems, (pp. 134165), New York: Guilford.

Cain, L., \& Pople, I. (2011). The dialect of the tribe: Interviewing highly experienced writers to describe academic literacy practices in business studies. Journal of Academic Writing, 1(1), 46-53.

Clughen, L., \& Hardy, C. (2011). Creating participatory writing cultures in UK higher educations. Journal of Academic Writing, 1(1), 71-78.

Ens, A.H., Boyd, K., Matczuk, L.A., \& Nickerson, L.A. (2011). Graduate students' evolving: Perceptions of writing collaboratively. Canadian Journal of Higher Education, 41(2), 62-81.

Ferguson, T. (2009). The 'write' skills and more: A thesis writing group for doctoral students. Journal of Geography in Higher Education, 33(2), 285-297.

Fulford, A. (2009). Ventriloquising the voice: Writing the university. Journal of Philosophy of Education, 43(2), 223-237.

Haas, S. (2011). A writer development group for master's students: Procedures and benefits. Journal of Academic Writing, 1(1), 88-99.

Hyland, K. (2002). Authority and invisibility: Authorial identity in academic writing. Journal of Pragmatics, 34, 1091-1112.

Kamler, B., \& Thomson, P. (2008). The failure of dissertation advice books: Toward alternative pedagogies for doctoral writing. Educational Researcher, 37(8), 507-514.

Krumer-Nevo, M., \& Sidi, M. (2012). Writing against Othering. Qualitative Inquiry, 18(4), 299-309.

Lea, M.R., \& Street, B. V. (2006). The 'academic literacies' model: Theory and applications. Theory Into Practice, 45(4), 368-377.
Lillis, T., \& Scott, M. (2007). Defining academic literacies research: Issues of epistemology, ideology and strategy. Journal of Applied Linguistics, 4(1), 5-32.

Maher, D., Seaton, L., McMullen, C., Fitzgerald, T., Otsuji, E., \& Lee, A. (2008). Becoming and being writers: The experiences of doctoral students in writing groups. Studies in Continuing Education, 30(3), 263-275.

Matthews, P. (1994). Sing me the creation. Stroud: Hawthorn Press.

Northedge, A. (2003). Enabling participation in academic discourse. Teaching in Higher Education, 8(2), 169-180.

Parker, J. (2002). A new disciplinarity: Communities of knowledge, learning and practice. Teaching in Higher Education, 7(4), 373-386.

Parry, S. (1998). Disciplinary discourse in doctoral theses. Higher Education, 36, 273-299.

Rosales, J., Moloney, C., Badenhorst, C., Dyer, J., \& Murray, M. (2012). Breaking the barriers of research writing: Rethinking pedagogy for engineering graduate research. Proceedings of the Canadian Engineering Education Association (CEEA12) Conference.

Sommers, N. (2008). The call of research: A longitudinal view of writing development. College Composition and Communication, 60(1), 152-164.

Tardy, C. M. (2005). "It's like a story": Rhetorical knowledge development in advanced academic literacy. Journal of English for Academic Purposes, 4, 325-338.

Wrigglesworth, J., \& McKeever, M. (2010). A genre-based, interdisciplinary approach linking disciplines, language and academic skills. Arts and Humanities in Higher Education, 9, 107-126.

Zerubavel, E. (1995). The rigid, the fuzzy and the flexible: Notes on the mental sculpting of academic identity. Social Research, 62(4), 1093-1106. 


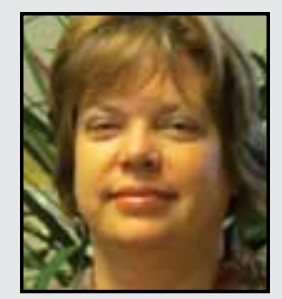

Cecile Badenhorst is an Assistant Professor in Adult/Postsecondary education in the Faculty of Education, Memorial University of Newfoundland. Her research focus is on teaching and learning in culturally and linguistically diverse postsecondary contexts, research writing, qualitative research, and adult learning. A particular area of interest for her is the pedagogy of academic research and writing; she has published three books in this area: Research Writing (2007), Dissertation Writing (2008), and Productive Writing (2010).

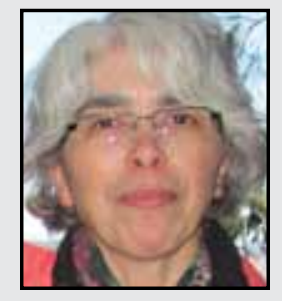

Cecilia Moloney is a Professor of Electrical and Computer Engineering with Memorial University. From 2004-2009 she held the NSERC/Petro-Canada Chair for Women in Science and Engineering, Atlantic Region (CWSEA). She is currently directing the MetaKettle Project at Memorial University as a legacy project from the CWSEA. Dr. Moloney's research interests include nonlinear signal and image processing methods, signal representations, human visual perception, radar signal processing, transformative pedagogy for science and engineering, and gender and science studies.

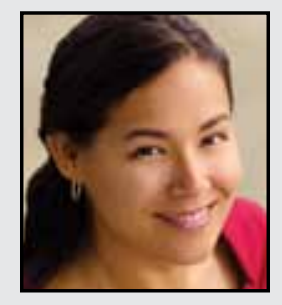

Janna Rosales works at the intersection of the sciences and humanities. She is a Visiting Assistant Professor in the Faculty of Engineering and Applied Science where she studies the social and ethical implications of technology, and teaches in the areas of ethics, communication, and professionalism. Her work explores the role that higher education plays in producing 21 st century global citizens, with a particular focus on creativity studies, leadership development, and dialogue education. 


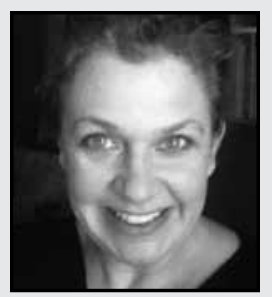

Jennifer Dyer is Assistant Professor of Communication Studies, Director of the Humanities Graduate Program, and Interim Director of the Interdisciplinary PhD at Memorial University. Her book Serial Images: The Modern Art of Iteration was published in 2011. She has also published and presented on Warhol, Hermeneutics, the aesthetic concept of Play, Francis Bacon, and semiotics in self-portraiture. She is currently writing a monograph on Art and Everyday Life. 